\title{
Study of Interfacial Pressure Distribution for Preloaded Bolted Connection
}

\author{
R. Mangalekar ${ }^{1 *}$, C. Ramdas ${ }^{2}$, B. Dawari ${ }^{3}$ \\ ${ }^{1}$ Assistant Professor, Sinhgad College of Engineering,Pune, India \\ ${ }^{2}$ Scientist, Composite Research Center, DRDO, Dighi, Pune, India \\ ${ }^{3}$ Associate Professor, College of Engineering Pune, India \\ \{rdmangalekar@gmail.com\}
}

\begin{abstract}
Analysis of double strap bolted lap joint was carried out using Finite Element Method (FEM). Angle of interfacial pressure distributionbetween the plates to be joined usingpreloaded bolted connection has been a debatable point though widely researched. Shigale's Pressure cone approach for the determination of the stiffness of the joint material had been used by many designers with fixed cone angle $30^{\circ}$. This angle of interfacial pressure distribution is affected by many factors including the plate thicknesses, bolt head diameter, plate material etc. Numerical modelling has been carried outon models with $8 \mathrm{~mm}, 12 \mathrm{~mm}$ and $16 \mathrm{~mm}$ thick cover platespre-compressed using M16 bolts. The results emphasize significance of the half cone angle in the calculation of stiffness of the cover plate in the bolted connection.
\end{abstract}

Keywords: Angle of interfacial pressure distribution, Finite Element analysis, Double strap bolted connection

\section{Introduction}

Structural joints are essential and critical elements of a structural assembly. But determination of joint stiffness has not been satisfactorily treated analytically until now, therefore, forcing many designers to handle it experimentally. The initial magnitude of bolt preload is the only parameter that can be controlled once the joint is subjected to the service load. There are several parameters like stiffness of connecting material, slip factor, bolt head radius, thickness ratios of plates etc which affect the behaviour of bolted connection. The angle of interfacial pressure distribution or half cone angle has been approximated by many designers since long. The studies have suggested different values of half cone angle obtained from different methods including experimental and numerical analysis. In this work, an attempt has been made to numerically simulate and study the effect of the above factors on the angle of interfacial pressure distribution i.e. half cone angle and contact pressure distribution.

\subsection{Bolt pretension}

The purpose of bolt preload is to place the bolted components in compression for improved resistance to either static or cyclic external loads. Therefore, the integrity of bolted joints depends on quantitative representation of the contact pressure distribution at the interface during design [1].IS 4000:1992 specifies the minimum bolt pretension for different bolt sizes. (Clause 7.2.1, B-1.2 and D-2.2).

\subsection{Contact pressure distribution in the connecting plates}

Distribution of the pressureat the connecting plate surfaces(Refer Fig. 1) has been studied through numerical and analytical studies. Analytical models have been developed to predict pressure distribution in bolted joints as a function of the contact radius. FernlundRotscher was one of the early researchers to calculate the spread of stress in a bolted joint [1].

B. Iyer, S. Nalbalwar and R. Pawade (Eds.)

ICCASP/ICMMD-2016. Advances in Intelligent Systems Research.

Vol. 137, Pp. 265-270.

(C) 2017. The authors - Published by Atlantis Press

This is an open access article under the CC BY-NC license (http://creativecommons.org/licens)es/by-nc/4.0/). 


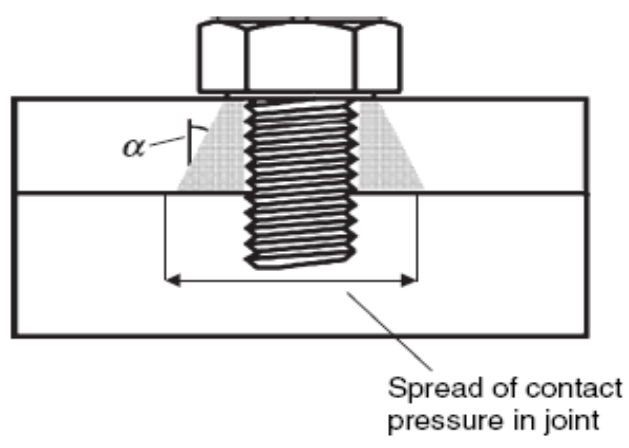

Fig. 1. Shigale's Pressure Cone approach [2]

Shigale [2] stated that half cone angle should be between $25^{\circ}$ and $33^{\circ}$ (assuming a washer is used). Marshal et al[3] applied an ultrasonic technique in their investigation to study bolted surfaces with no washer and with plain and spring washers using two different interfaces (turned and ground). It was found out that surface profile and washers affect spread of the contact pressure at bolted interface. Consequently, it was shown that it is inappropriate to use a fixed contact spread angle, as suggested by some other studies, to determine joint stiffness for bolted joints with different contact surface profiles.

\subsection{Stiffness of the members in the bolted connections}

Lehnhoff et al [4] emphasized that the pressure angle of $45^{\circ}$ proposed by Rotscher overestimates the clamping zone. They proposed an analytical model to calculate the member stiffness and the stress distribution of bolted joints for various bolt sizes, thicknesses and materials of the members. It was assumed that there was a uniform pressure within a frustum cone envelope under bolt head. They recommended a fixed standard pressure angle of $30^{\circ}$ as a better value for calculating the joint material stiffness:

$$
K m=\frac{(\pi E d \tan \alpha)}{2 \ln [(\operatorname{ltan} \alpha+\mathrm{dw}-\mathrm{d})(\mathrm{dw}+\mathrm{d}) /(\operatorname{ltan} \alpha+\mathrm{dw}+\mathrm{d})(\mathrm{dw}-\mathrm{d})]}
$$

Where $d_{w}$ isdiameter of the contact under the bolt head and $l$ iseffective grip.

Marshall et al [3]in his earlier study had mentioned that the angle of interfacial pressure distribution makes a great difference in the determination of the stiffness of the joint.

\section{Finite Element Modelling}

The experimental method becomes difficult to comprehend when the measurement of interfacial pressure distribution is of main concern. Thus numerical modelling technique i.e. Finite Element modelling was adopted.The model geometry adopted was conforming to the laboratory standards. These standards are compared with the IS 4000:1992 standards test specimen requirement (Refer Table 1). The model of double cover strap joint with M16 bolt was studied(Refer Fig.2). The holes were oversized holes $(d+3)$.

The study was restricted to linear material model. However, contact non-linearity has been considered in the modeling.Out of several methods available for modeling bolt pre-tension, the method adopted herewas to define the pretension load at the center of the shank by virtually cutting it into the two halves.

8 Noded brick element was used in the FE modelling because of its accuracy and suitability for contact problems.No special elements were required to define contact between the surfaces. The two types of contacts defined were- Normal contact accounts for the hard contact to avoid the penetration of the parts into each other and transfer the normal load and the other- tangential contact which accounts for frictional load transfer between the surfaces. The model was fixed at one end (Refer Fig.2 b). 


\begin{tabular}{|c|c|c|c|c|}
\hline \multirow{7}{*}{ Table 1} & Sr. No. & Parameter & IS & Lab standards \\
\hline & 1 & Length of cover plate & $10 \mathrm{~d}=160 \mathrm{~mm}$ & $166 \mathrm{~mm}$ \\
\hline & 2 & Width of cover plate & $6 \mathrm{~d}=96 \mathrm{~mm}$ & $80 \mathrm{~mm}$ \\
\hline & 3 & Cover plate thickness & $\left(\frac{d}{-}+3\right)=11 \mathrm{~mm}$ & $12 \mathrm{~mm}$ \\
\hline & 4 & c/c distance of bolt holes & $6 \mathrm{~d}=96 \mathrm{~mm}$ & $86 \mathrm{~mm}(5 \mathrm{~d} \min )$ \\
\hline & 5 & Edge distance & $3 \mathrm{~d}=48 \mathrm{~mm}$ & $40 \mathrm{~mm}$ \\
\hline & 6 & End distance & $2 \mathrm{~d}=32 \mathrm{~mm}$ & $40 \mathrm{~mm}$ \\
\hline
\end{tabular}

specimen dimension from IS 4000:1992 and Lab standards

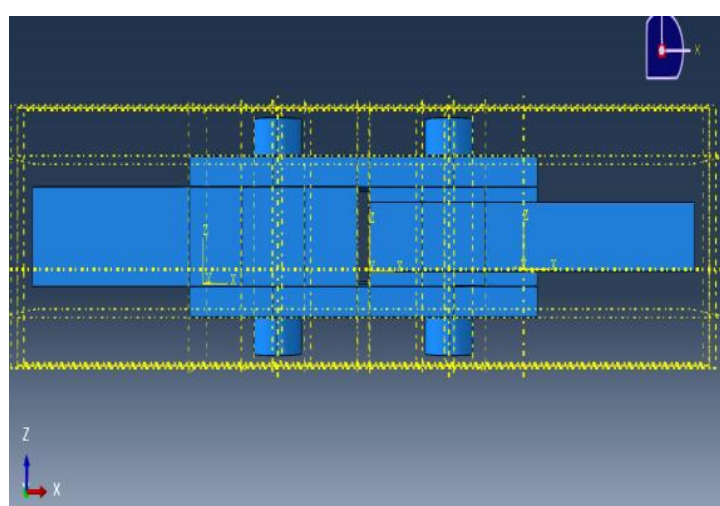

(a)

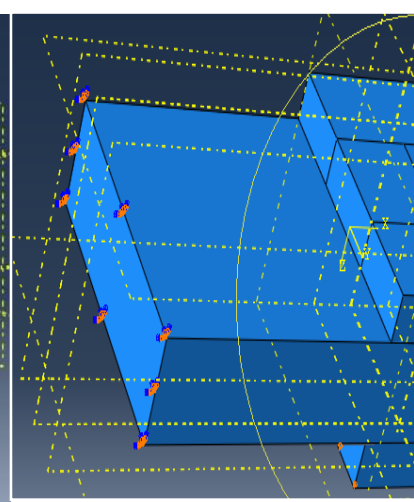

(b)

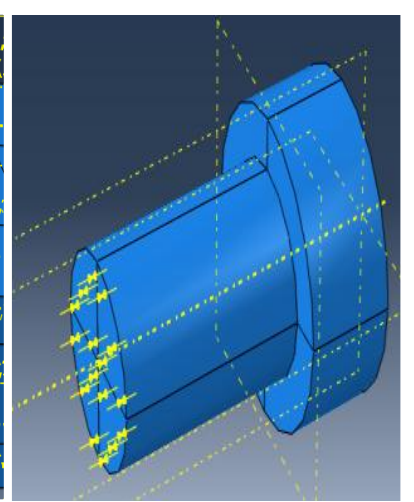

(c)

Fig. 2. a) Model geometry b) BC-fixed and c) Bolt load at centre of shank

\section{Results and Discussion}

Effect of different parameter on the interfacial pressure distribution was studied. There was no external load in the first stage of analysis, where the angle of interfacial pressure distribution onlydue to the bolt preload was analysed. In later stage, external shear load was applied and failure of the model was checked. The high strength material used for the metal plates in the analysisprevented their yielding.

\subsection{Effect of bolt preload magnitude on interfacial pressure distribution}

Bolt pre-tension increasing from $80 \mathrm{kN}$ to $130 \mathrm{kN}$ was applied on M16 bolt. The Interfacial pressure distribution was plotted on the top of the cover plate and on the top of the friction plate. (Refer Fig. 2). 


\begin{tabular}{|l|l|l|l|l|}
\hline Magnitude of Bolt Preload (kN) & 80 & 100 & 110 & 130 \\
\hline Radius of separation (from hole edge) $\mathbf{~ m m}$ & 26.26 & 26.5 & 26.6 & 26.8 \\
\hline
\end{tabular}

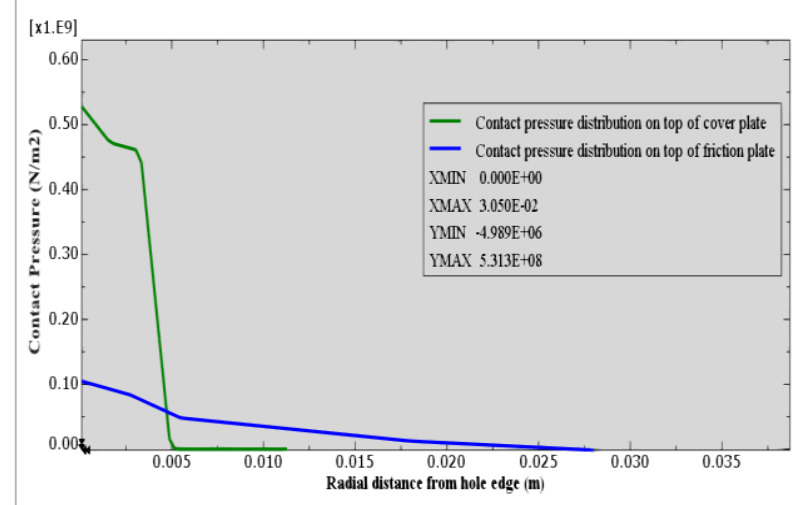

Fig. 3. Interfacial pressure distributions for $80 \mathrm{kN}$ bolt load on $8 \mathrm{~mm}$ cover plate model

Table 2 shows the effect of bolt preload magnitude on the distribution of the interfacial pressure. It can be seen that radius of separation is not much affected by the bolt preload magnitude.

Table 2 Radius of separation with the different bolt preloads on $8 \mathrm{~mm}$ cover plate model

\subsection{Effect of plate thickness on interfacial pressure distribution}

The models with the $12 \mathrm{~mm}$ and $16 \mathrm{~mm}$ thick cover plate were studied to know the effect of the cover plate thickness on the interfacial pressure distribution. Width of the plate required to dissipate the contact pressure completely is found insufficient in case of the $16 \mathrm{~mm}$ thick cover plate model. Table 3 shows radii of separations for $8 \mathrm{~mm}$ and $12 \mathrm{~mm}$ cover plates. It is observed that radius of separation increases with the increase in the plate thickness.

Table 3 Radius of separation for different plate thicknesses

\begin{tabular}{|l|c|c|}
\hline \multirow{2}{*}{ Plate Thickness } & Bolt Preload $(\mathbf{k N})$ & $\begin{array}{c}\text { Radius of separation from hole edge } \\
(\mathbf{m m})\end{array}$ \\
\hline \multirow{2}{*}{$8 \mathrm{~mm}$} & 80 & 26.26 \\
\hline \multirow{2}{*}{$12 \mathrm{~mm}$} & 130 & 26.83 \\
\cline { 2 - 3 } & 80 & 30.02 \\
\cline { 2 - 3 } & 130 & 30.04 \\
\hline
\end{tabular}

The angle of interfacial pressure distribution has been calculated by connecting the two points of zero contact pressure on the cover plate and top of middle plate respectively. Table 4 shows angles of interfacial pressure distributionfor different cover plate thicknesses.

Table4 Angle of interfacial pressure distribution (in degrees) for different steel cover plate thicknesses

\begin{tabular}{|l|l|l|l|l|l|l|}
\hline Plate thickness & \multicolumn{2}{|l|}{$\mathbf{8} \mathbf{~ m m}$} & \multicolumn{2}{l|}{$\mathbf{1 2} \mathbf{~ m m}$} & \multicolumn{2}{l|}{$\mathbf{1 6} \mathbf{~ m m}$} \\
\hline Bolt load kN & 80 & 130 & 80 & 130 & 80 & 130 \\
\hline
\end{tabular}




\begin{tabular}{|l|l|l|l|l|l|l|}
\hline For 0 MPa & 69.42 & 69.91 & 64.84 & 64.42 & - & - \\
\hline For 10 MPa & 61.62 & 65.72 & 56.17 & 61.55 & 53.3 & 57.79 \\
\hline
\end{tabular}

\subsection{Effect of material and coefficient of friction on angle of interfacial pressure distribution}

Contact pressure distribution on top of $12 \mathrm{~mm}$ Aluminium cover plate was found out from the numerical simulation. The radius of separation was $29.28 \mathrm{mmfor}$ this model. It was found that there is a minor effect of the material and the coefficient of friction of the surfaces on interfacial pressure distribution.

\subsection{Effect of angle of interfacial pressure distribution on the stiffness of the joint}

As it is seen from the Table 5, the dimensionless stiffness is highly dependent on the half-apex angle. The dimensionless stiffness jumps from 0.77 to 2.6 for the $8 \mathrm{~mm}$ cover plate for half cone angles $30^{\circ}$ and $70^{\circ}$ degrees respectively.

Table 5 Dimensionless stiffness for different values of half apex angle

\begin{tabular}{|c|c|c|}
\hline \multirow{2}{*}{$\boldsymbol{\alpha}$} & Dimensionlessstiffnessfor used cover plate thicknesses \\
\cline { 2 - 3 } (Degrees) & $\mathbf{1 2 \mathbf { m m }}$ & $\mathbf{8 m m}$ \\
\hline 30 & 0.73 & 0.77 \\
\hline 40 & 0.95 & 1.00 \\
\hline 50 & 1.25 & 1.301 \\
\hline 60 & 1.706 & 1.75 \\
\hline 70 & 2.55 & 2.603 \\
\hline
\end{tabular}

\subsection{Effect of meshing on the interfacial pressure distribution:}

One of the observations in the study was change in the location of the maximum contact pressure on the cover plate with the meshing. As the mesh is made finer, the maximum contact pressure on the cover plate moves towards the hole edge (ref Fig.4).Ziada (1980) [7] observed that the peak pressure occurs as a ring under the edge of the bole head. The behaviour observed in this study might be related to the use of finite elements in the analysis which needs further investigation.
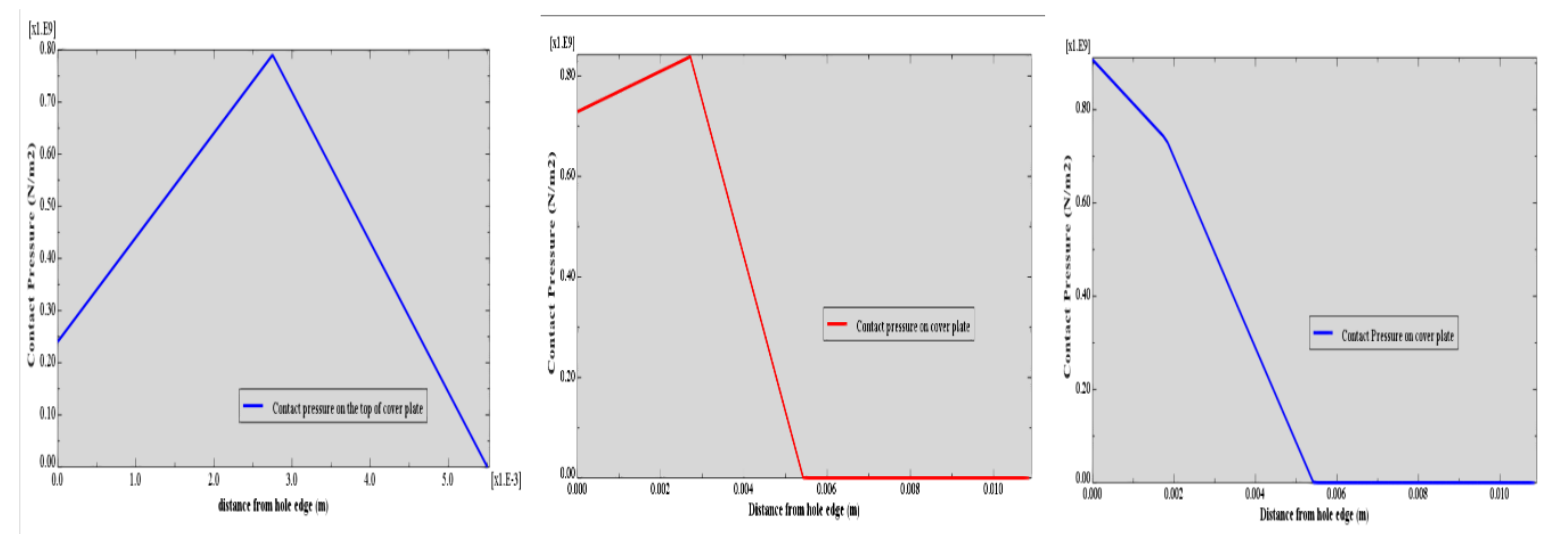

Fig. 4. Location of maximum contact pressure on cover plate (mesh getting finer from left to right) 


\section{Conclusions}

This study underlines importance of determination of accurate angle of interfacial pressure distribution in connecting plates in the bolted connection for calculation of joint-member stiffness. The values of angle of interfacial pressure distribution for cover plates observed are $64^{0}$ and $69^{\circ}$ for model of double cover strap joint. Also it is was observed that angle of interfacial pressure distribution in metal cover plate of double cover strap joint is affected more by the cover plate thickness than due to its material and coefficient of friction. The important observation in this numerical study was that the finite element mesh size affects the location of the maximum contact pressure on the cover plate.

\section{References}

[1]. I. Fernlund, "A Method to Calculate the Pressure between Bolted and Riveted Plates"Transaction of Chalmers University, No.25, Gothenburg Sweden, 1961.

[2]. J. Shigale, C. Mischke, "Mechanical Engineering Design" 8th edition. McGraw-Hill Publication, 2008

[3]. M. B. Marshall, R. Lewis and R. Dwyer-Joyce, "Characterization of Contact Pressure distribution in Bolted Joints" International Journal for Experimental mechanics, Volume 42, Issue 1, 31-43, February 2006

[4]. T. Lehnhoff, K. Ko, and M. McKay, “Member Stiffness and Contact Pressure Distribution of Bolted Joints"Journal of Mechanical Design. 116(2): p. 550-557. 1994

[5]. M. Shibahara and J. Oda, "On Clamping Stiffness of Abutments in Bolted Joints", Transactions of the JSME, Vol. 72, No. 611, pp1611-1619, 1969

[6]. Y. Ito, J. Toyoda, and S. Nagata, “Interface Pressure Distribution in a Bolt-Flange Assembly” Journal of Mechanical Design-Transactions of the ASME, 101(2): p. 330-337. 1979.

[7]. H. Ziada, and A.K. Abdul El Latif, "Load, pressure distribution and contact area in bolted joint". Proceedings of Institution of Engineers (India), Journal of Mechanical Engineering, 61(93-100), 1980.

[8]. J. Wileman, M. Choudhury and I. Green, "Computation of member stiffness in bolted connections", ASME Publications, Journal of mechanical Design., 113 (4) 432-437, 1991

[9]. J. Bickfords, “An Introduction to design and behavior of bolted joints" Marcel DeccarInc., $3^{\text {rd }}$ edition, 1997

[10]. J. Musto and N. Konkle, "Computation of Member Stiffness in the Design of Bolted Joints", ASME J. Mech. Des., November, 127, pp. 1357-1360,2006

[11]. N. L. Pedersen and P. Pedersen "On prestress stiffness analysis of bolt plate contact assemblies," Arch. Appl. Mech., 75-88, 2008.

[12]. F. Gunbrin, "Prediction and modeling of fastener flexibility using FE", Department of Mechanical Engineering, Linköping University, 2008 